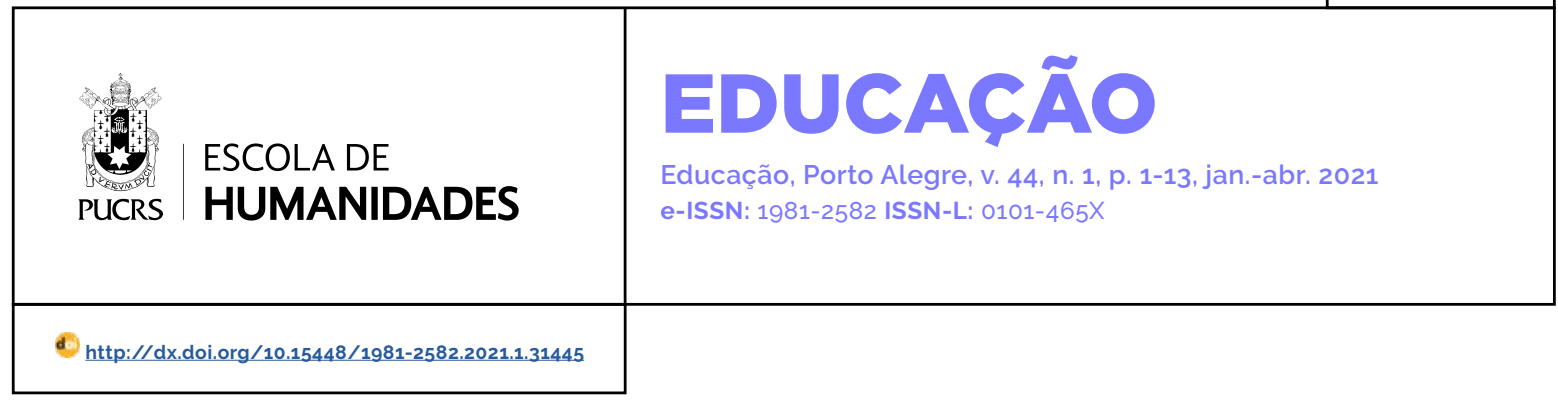

SEÇÃO

\title{
Comparando discursos sobre educação continuada de professores entre Brasil e Argentina
}

\author{
Comparing speeches about teacher's continuing education between Brasil and Argentina \\ Comparación de discursos sobre educación continua del profesorado entre Brasil y \\ Argentina
}

Elaine Gomes Matheus
Furlan $^{1}$

orcid.org/0000-0002-5413-7964

elainefurlan.ufscar@gmail.com

Alda Junqueira Marin² orcid.org/0000-0002-2120-338X profaldajunqueiramarin@gmail.com

Recebido em: 18 jul. 2018. Aprovado em: 14 ago. 2020. Publicado em: 21 jun. 2021.

\section{(c) (1)}

Artigo está licenciado sob forma de uma licença Creative Commons Atribuição 4.0 Internacional.
Resumo: Este trabalho é parte de projeto coletivo de pesquisa mais ampla sobre novos modelos de formação de professores com alguns objetivos abrangendo comparações do Brasil e paises da América Latina. No decorrer da pesquisa surgiu uma questão intrigante, qual seja, as semelhanças e as diferenças no que se refere a discursos e práticas de formação continuada de professores. Neste artigo, portanto, focalizam-se intervenções que compuseram agendas politicas nessa área. Os dados foram obtidos por meio de entrevistas e de documentos representados por leis, normativas e projetos de formação. Destacam-se, nessas intervenções, os discursos, mas também algumas práticas decorrentes. Foram tomados como base de análise os termos utilizados no Brasil e na Argentina, tais como: formação em serviço e fora do serviço; aperfeiçoamento; capacitação: formação contínua; e educação continuada. Esses termos e suas variações são analisados nas relações com as agendas políticas das últimas décadas com suporte da concepção de que a comparação permite a compreensão de como são propostas tais ações em cada país. As análises decorrem do uso da concepção relacional com politicas internacionais e com perspectiva da sociologia da cultura. Palavras-chave: educação continuada, análise de termos, comparação entre Brasil e Argentina

Abstract: This paper is a part into a collective research project about new models for teacher's education with some objectives comparing Brasil and countries from Latin America. During the realization of the research aroused the question that sharpened our curiosity about the similarities and differences of speeches and practices of continuing teacher's education. In this article are focused interventions from political agendas in this area. Data were obtained with interview and documents as laws, norms and projects. We distinguished the speeches but also some current practices. The analysis basis was the words used in Brasil and Argentina as: in and out service education; improvement; convincing; continuing education; continuing formation. These words and its variations are analyzed with the relations of political agendas from the last decades with the support of the conception that the comparison helps understand about how these agendas are proposed and realized in each country. The analysis are made connecting international political and with some concepts from the sociology of culture.

Keywords: continuing education, analysis of words, comparison between Brasil and Argentina

Resumen: Este trabajo forma parte de un proyecto colectivo de investigación más amplio sobre los nuevos modelos de formación del profesorado, con algunos objetivos, incluyendo comparaciones de Brasil y de paises de América Latina. Durante la investigación surgió una pregunta intrigante, a saber, las similitudes y diferencias con respecto a los discursos y prácticas de la formación continua del profesorado. Sin embargo, en este trabajo, el enfoque de las intervenciones que forman parte de las agendas políticas en esta área. Los datos fueron recolectados 
a través de entrevistas y documentos representados por las leyes, reglamentos y proyectos de formación. Se destacan en estas intervenciones, discursos, sino también algunas prácticas decurrentes. Se tomaron como base para el análisis de los términos utilizados en Brasil y Argentina, como, la capacitación en servicio y fuera de servicio, perfeccionamiento, capacitación, la formación continua; la educación continua. Estos términos y sus variaciones se explican en las relaciones con las agendas politicas de las últimas décadas para apoyar la opinión de que la comparación permite la comprensión de cómo se proponen este tipo de acciones en cada país. El resultado del análisis decurren de la concepción relacional con las politicas internacionales y con perspectiva de la sociología de la cultura.

Palabras clave: educación continua, el análisis de los términos, comparación entre Brasil y Argentina

Tomar a educação continuada como foco de estudos para compreensão da educação implica várias considerações preliminares. Há aspectos relativos à origem de tais preocupações e seu incremento desde meados dos anos de 1960; há diferentes concepções e desdobramentos delas nas ações propostas ou efetivadas; há aspectos jurídico-formais; há variadas implementações conforme a esfera de atuação dos sujeitos; há diferentes influências de ações politicas em âmbitos macro e, também, micro dos paises e de fora deles. Qualquer consideração nesse conjunto enseja questões intrigantes que possam orientar novos estudos também na perspectiva comparativa.

No estudo aqui relatado, a perspectiva comparada de análise volta-se para os discursos sobre a modalidade da educação continuada na formação geral de professores focalizando diferentes aspectos desses âmbitos exemplificados. É parte de um projeto coletivo de pesquisa mais ampla sobre novos modelos de formação de professores, ${ }^{3} \mathrm{com}$ alguns objetivos abrangendo comparações entre Brasil e paises da América Latina, entre eles a Argentina, focalizando, sobretudo, os últimos vinte anos com a interferência e o acirramento das reformas neoliberais.

Durante o período de coleta de informações sobre a formação em serviço de professores na Argentina e no Brasil e a existência de diferentes circunstâncias que cercam essa esfera educacional, a educação continuada ganhou relevo, entre outros pontos, por algumas diferenças entre as situações dos dois paises como: os periodos de formação, as temáticas e os modos de realização dessas ações que nem sempre coincidem entre si. Dentre esses pontos surgiu uma questão intrigante, qual seja a das semelhanças e das diferenças no que se refere a discursos e práticas de formação continuada de professores. Essa questão constitui um recorte na pesquisa considerando a profusão de informações obtidas ao longo dos contatos com os profissionais argentinos.

Nas visitas à Argentina procurou-se entender o sistema educacional e seus desdobramentos acerca da formação em serviço com ajuda da documentação disponivel, além de entrevistas com algumas pessoas como professores universitários, funcionários do sistema educacional e demais agentes que estudaram e vivenciaram tais situações, contribuindo com informações estratégicas para a coleta de dados no sentido de entender o contexto social, político, econômico, histórico e, principalmente, educacional do pais nos últimos 20 anos.

Este texto, portanto, abrange súmula de intervenções que compuseram agendas políticas nessa área e algumas balizas legais e teóricas para um estudo de natureza comparativa, para então apresentar os procedimentos e os dados da pesquisa articulando-os em suas variações.

\section{Alguns apoios}

As pesquisas no campo educacional mantêm relações fundamentais com as ações politicas e essas, em particular, não ficam alheias a tais necessidades de focalizações. Assim, neste item, inicialmente são apontados alguns dados sintéticos relativos às facetas juridico-formais da formação de professores e sua relação com a educação continuada, sobretudo por tais regulamentações implicarem modificações ou tentativas de reformas educacionais, incidindo nas temáticas das ações de formação continuada realizadas com os professores. A seguir, são apresentados alguns conceitos que orientaram a realização do estudo.

Na Argentina, Birgin (2012) compila um debate sobre a formação dos professores em exercício,

\footnotetext{
3 Tratou-se de projeto temático financiado pela Fundação de Amparo à Pesquisa do Estado de São Paulo, Brasil, envolvendo várias universidades brasileiras.
} 
localizando três grandes periodos relativos aos diferentes discursos sobre a educação continuada e explicitando que não tem como objetivo uma reconstrução etimológica nem a recuperação dos distintos significados concedidos nos distintos contextos (nas estruturas, nas agências governamentais, documentos internacionais, leis e normas locais, dispositivos formativos, documentos acadêmicos etc.), mas o que interessa é recuperar os momentos de surgimento e de uso dos termos mais frequentes. A autora apresenta uma perspectiva descritiva sobre a institucionalização da formação docente em exercício na Argentina, considerando suas particularidades na região e distinguindo cada período.

O primeiro abrange desde os finais dos anos 1950 até meados dos anos 1980 referindo-se ao período da formação docente no qual os instrumentos legais, que regulam o uso do termo aperfeiçoamento, ${ }^{4}$ são os estatutos docentes, observando-se linhas políticas e graus de institucionalização ainda tênues. Esse período não foi aprofundado neste estudo, no entanto, alguns aspectos podem ser abordados em relação aos dados coletados durante as visitas à Argentina, destacando que o sentido da formação docente está incorporado na carreira e no trabalho dos docentes argentinos desde a origem do sistema educativo. Várias condições favoreceram o desenvolvimento de ações politicas para melhorar e ampliar a formação docente; as transformações econômicas, sociais e científicas desencadea- das na década de $1970^{5}$ colocaram em crise os sistemas educativos dos países, promovendo, na década de 1980, uma discussão acadêmica ${ }^{6}$ sobre questões da formação em serviço7 incluindo a opinião dos próprios docentes a respeito da formação que tiveram. Essa época pode ser caracterizada como o segundo momento, de acordo com Birgin (2012), iniciado em meados dos anos 1980 podendo vincular-se aos ciclos de reformas educativas da época, em que capacitação ${ }^{8}$ é o termo de maior uso, destacando que atualização ${ }^{9}$ também manifesta um crescimento relativamente notável, ambos fazendo referência à formação inicial como insuficiente ou incapaz de formar para as novas exigências educacionais.

Por último, desde meados dos anos 1990, registra-se o início de outras noções que nomeiam a formação pós-inicial. Segundo Serra (2004), dos debates iniciados na década de 1980 emergiram a necessidade de integrar a formação inicial e a continuada, além da ampliação dos Institutos de Formação Docente e das suas funções, promovendo algumas medidas relevantes: na Resolução n. ${ }^{\circ} 9$ de 1990, do Conselho Federal de Cultura e Educação, o papel central do Ministério da Educação e sua influência na agenda de discussão dos acordos do Conselho Federal de Cultura e Educação, procurando exercer mecanismos regulatórios e a sanção da Ley Federal de Educación, em 1993, definindo objetivos para essa esfera de formação. Neste sentido, a década de 1990 apresenta aspectos que marcaram as reformas que se

\footnotetext{
4 Este estudo apoia-se na definição de Marin (1995) que aborda o aperfeiçoamento no sentido de corrigir algumas condutas, adquirindo maior grau de instrução sendo possivel deixar alguns saberes fora de foco, possibilitando a aquisição de outros, de forma que as ações e os pensamentos indesejáveis, inúteis ou pouco adequados às novas necessidades possam ser substituidos por outros mais relevantes, coerentes e necessários.

5 Este contexto é discutido por Davini (1998) e Riquelme (1998), dentre outros.

- As políticas relativas à transformação do sistema educativo começaram a ganhar força com o retorno a uma nova ordem política no país, buscando democratizar a vida cotidiana das escolas em um novo modelo. Um marco importante foi o Congreso Pedagógico Nacional (1986-1988) marcando amplas discussões da sociedade a respeito de temas relativos à educação e suas urgências (Serra, 2004).

7 O termo "em serviço" é denominado para qualquer ação executada no horário de trabalho dos professores, seja no ambiente de trabalho ou não em que não somam pontos (puntaje) para a classificação dos docentes; na Argentina a maioria dos cursos é na modalidade presencial, dentro das escolas, no horário de trabalho e envolvendo todos os atores necessários, com direito a substitutos para suas atividades. Embora alguns entrevistados reconheceram que "é dificil obrigar alguém a fazer alguma coisa neste pais", geralmente esse tipo de formação é obrigatória. Por outro lado, a formação "fora de serviço" (realizada em horários alternativos ao trabalho) é considerada como uma iniciativa pessoal para aperfeiçoamento profissional e tem objetivos diversos, porém o principal deles é a obtenção de pontos para melhorar a classificação em busca de se tornarem efetivos, trocar/escolher a escola que querem trabalhar ou para ascensão de cargo, ou seja, para direção da escola.

8 Capacitação é apresentado aqui apoiado na discussão feita por Marin (1995) como termo ou conceito que seja expresso por ações no sentido de obter patamares mais elevados de profissionalidade, ou seja, tornar capaz ou habilitar por um lado e, por outro lado, o sentido de convencimento ou persuasão, promovendo inculcação de ideias, processos e atitudes como verdades a serem simplesmente aceitas. 9 No Brasil, o termo reciclagem esteve muito presente e apareceu como significado de "atualização pedagógica", sobretudo na década de 1980, tanto nos discursos cotidianos e da imprensa, quanto qualificador de ações de órgãos públicos e privados, envolvendo profissionais de várias áreas, incluindo a de educação (Marin, 1995).
} 
estenderam pela América Latina trazendo novas propostas curriculares e mudanças nos enfoques epistemológicos e didáticos que conduziram uma revolução do discurso em torno dos docentes. Isso retrata um momento de transição em relação à nomenclatura, englobando alguns termos utilizados desde a década de 1980, incluindo novos e reforçados na década seguinte. Entretanto, concordamos com Birgin (2012) quando ela alerta que "los mismos términos adquieren significados diferentes en los mismos o en otros tiempos" (p. 21). Portanto, tomemos alguns cuidados em considerarmos "sinônimos" alguns termos e suas variações quando analisados nas relações com as agendas políticas das últimas décadas.

No Brasil, a primeira preocupação com a educação continuada aparece na década de 1960 com a primeira Lei de Diretrizes e Bases com vigência até 1996, quando foi promulgada a segunda lei geral da educação do país; porém, os discursos sobre tal formação aparecem de maneira diversificada em diferentes circunstâncias ao longo de todo esse periodo, até o momento atual. Ao longo desse meio século, as regulamentações sobre a educação continuada estiveram sempre ligadas à formação geral e com a perspectiva de melhoria para o desempenho da função docente, mas, também, articuladas a alterações das condições salariais, com estatutos e planos de carreira previstos. Entre a primeira lei geral, em 1961, e a segunda (Saviani, 1997), no Brasil ainda houve outra legislação federal ${ }^{10}$ que reorganizou toda a base do ensino fundamental unindo dois segmentos (a escola primária e o ginásio) em uma só escola de oito anos, assim como reorganizou o ensino médio dando-lhes outras características e funções educativas (Boynard et al., 1972). Tais alterações trouxeram, como se pôde prever, enormes necessidades de estudos para os professores e outros agentes educacionais acompanharem e implementarem as mudanças previstas posto que as consequências propostas para a vida interna das escolas foram muitas, bastante acirradas, alteradas legalmente no último período que ainda está em vigência desde a década de 1990. Nessa legislação encontra-se a presença de artigos especificos abordando o tema aqui discutido.

Em ambos os países, várias tentativas de reformas ocorreram, durante a década sob nosso interesse, provocando o surgimento de diversas decorrências procurando reconfigurar os sistemas educativos a partir das medidas sugeridas pelo Banco Mundial - reforma do financiamento e administração da educação, recomendação para autonomia das instituições, forte atenção aos resultados, sistema de avaliação da aprendizagem e maior articulação com o setor privado (Shiroma et al., 2011) - e financiadas pelo Banco Interamericano de Desenvolvimento, incidindo, então, fortemente sobre a educação continuada considerada estratégia mais rápida, mais econômica e de maior alcance do que a formação inicial (Torres, 1996) e contando com profissionais capacitados de outros países (Davini, 1998) tanto na Argentina quanto no Brasil.

Embora sob a mesma orientação internacional, desde o pós-guerra, pela breve apresentação dos períodos já é possivel vislumbrar algumas diferenças entre os dois paises, o que nos exige a explicitação dos fundamentos conceituais para a realização das análises.

Entender o esquema de um estudo de natureza comparativa implica o domínio de conceitos relativos a esta área acadêmica aqui focalizada. Um dos autores de referência no campo é Ferrer (2002), que nos permite acesso fundamental ao cenário do conhecimento construido em que se detectam as tensões e os consensos existentes na atualidade. Segundo o autor:

saber responder a lo que se demanda de los
comparatistas en cada una de las instituciones
y por parte de los nuevos consumidores no es
una tarea fácil, pues los intereses, objetivos y
público destinatario de sus acciones es muy
diverso. (Ferrer, 2002, p. 204)

Aceitando tal alerta, nosso estudo pretende ao mesmo tempo considerar que nosso propósito é o de aceitar a orientação teórica de "proporcionar un entendimiento general de los fenómenos" 
(Oliveira citado por Ferrer, 2002, p. 204) e também concordar com Pereyra, a partir de Przeworski, quando diz que "la investigación comparada no consiste en comparar sino en explicar" (Pereyra citado por Ferrer, 2002, p. 204).

Além desses dois conceitos que explicitam características epistemológicas dessa área de conhecimento, também Liegle nos auxilia a situar o escopo do estudo ao apontar que " $L a$ perspectiva sistemática consiste en la tentativa de identificar las fuerzas ocultas que hay en la estructura del sistema educativo, de explicar los rasgos comunes y diferencias en la interacción entre cultura y educación (...)" (Liegle citado por Ferrer, 2002, p. 205, grifos do autor).

Para tanto, também nos aproveitamos de um dos elementos propostos por Nóvoa - os discursos - considerados por Ferrer (2002) como um dos temas relevantes da época contemporânea, qual seja, "comprender cómo cada época y cada lugar construyen sus propios autores y se apropian de sus practicas discursivas" (Nóvoa citado por Ferrer, 2002, pp. 207-208).

Esses conceitos nos levam, ainda, a considerar as reflexões de Bourdieu e Passeron em um texto divulgado na França, na década de 1960. Dizem eles, a partir de vários elementos analisados, que a comparabilidade de sistemas educacionais é problemática se tomarmos indicadores comuns para tempos e lugares diversos, principalmente, no que tange à eficácia e à produtividade dos sistemas, no contexto do ensino universitário analisado por eles. Recusando o abstracionismo representado pela ilusão com o uso padronizado de vocabulário e de ausência do exame de relações com os sistemas ou grupos sociais em que a atividade educativa acontece, além de diferentes exigências quanto a diplomas - e também recusando o intuicionismo - ou seja, a assunção de afinidades entre valores dos sistemas de ensino sem o exame prévio das relações com outros aspectos sociais - ambas características que permeiam, muitas vezes, as comparações, os autores consideram possivel a comparação levando-se em conta as funções cumpridas pelos sistemas de ensino - de conservadorismo, de socialização e de preparo para que os estudantes tomem seu lugar na sociedade - em cada foco de análise e em seu contraponto de mudança no conjunto dos seus aspectos sociais. Interesses ideográficos, portanto, com certa abstração de registros das realidades e não só de ideias, não podem ignorar certas particularidades dos sistemas nacionais, mas, também, não podem reduzir as características às originalidades únicas de cada sistema. Tais considerações, por vezes, estão ausentes em estudos como esse (Bourdieu \& Passeron, 1979). Entretanto, nos auxiliam na busca da identificação das similaridades e diferenças.

\section{A pesquisa: procedimentos e dados}

Os estudos foram realizados no início desta década, tendo como objetivo investigar as similaridades e as diferenças nas propostas desenvolvidas nos modelos de formação em serviço na América Latina e, neste caso, especificamente na Argentina, quando se passou a focalizar, também, as questões enunciadas sobre os discursos em relação à educação continuada. Conforme os conceitos apresentados, inicialmente foi necessário um grande esforço em relação ao entendimento do contexto histórico, social, político e cultural para apreensão de aspectos, até então, desconhecidos, por meio de um mergulho em muitas leituras, consultas a documentos, além de buscar interagir com profissionais, preferencialmente ligados a processos de formação, para apreensão de elementos importantes para o andamento da pesquisa. Foi importante apreender a perspectiva da cultura argentina em relação à rede de contatos, ou seja, a pesquisa foi muito bem-recebida e contou com muita disposição e ajuda dos sujeitos envolvidos em todos os lugares visitados; no entanto, sempre era frisado o encaminhamento e/ou a indicação como um fator importante para essa participação. Assim, os dados argentinos foram obtidos por meio de entrevistas - com funcionários do Instituto Nacional de Formação Docente (INFD) que trabalham com capacitação docente na Capital Federal; formadores (atuais e aposentados) da escola de capacitação da cidade de Buenos Aires (CEPA); professores que traba- 
lham há longa data como formadores em outros cursos de capacitação docente e professores atuantes na educação básica e que participam dos cursos de capacitação nas cidades de Buenos Aires e nas províncias de Córdoba e San Luís - e documentos representados por leis, normativas e projetos de formação docente.

Os dados da realidade brasileira foram obtidos com base em bibliografia e documentos oriundos de coletas empíricas junto a profissionais da educação e disponiveis no projeto coletivo já citado.

É importante destacar, inicialmente, a constante interferência dos organismos multilaterais sobre as realidades brasileira e argentina desde os anos de 1970, com o alerta, por exemplo, do Banco Mundial desde essa época para que os analistas econômicos "considerassem e agissem sobre o que acontecia na sala de aula" (Coraggio, 1996, p. 97) e, mais ainda: "todas as receitas que puderam ser vistas desde então como resposta à crise dos sistemas educacionais já estavam elaboradas" (Coraggio, 1996, p. 97).

Constatou-se, assim, que no Brasil e na Argentina, o primeiro periodo foi marcado pelos discursos voltados ao aperfeiçoamento dos professores. $\mathrm{Na}$ Argentina esse foi o termo mais utilizado para referir-se ao periodo da formação docente que vai de 1950 a 1980, exigindo revisões nas ações e nos discursos, dadas as características do periodo.

No Brasil, a legislação da década de 1970 - Lei que Fixa Diretrizes e Bases do Ensino de $1 .{ }^{\circ} \mathrm{e}$ $2 .^{\circ}$ graus (Boynard et al., 1972) - preconiza a necessidade de outra formação além da formação inicial em dois artigos:

Art. 38 - Os sistemas de ensino estimularão, mediante planejamento apropriado, o aperfeiçoamento e atualização constante dos seus professores e especialistas de Educação.

Art. 39 - Os sistemas de ensino devem fixar a remuneração dos professores e especialistas de ensino de $1^{\circ}$ e $2^{\circ}$ graus, tendo em vista a maior qualificação em cursos e estágios de formação, aperfeiçoamento ou especialização, sem distinção de graus escolares em que atuem. (pp. 36-37, grifos nossos)

Esse foi o periodo em que surgiu a preocupação oficial com tal formação, também denominada de aperfeiçoamento tal como na Argentina, pois passou a constar da legislação a necessidade e a possibilidade de realização de tais ações como decorrência da expansão da oferta da escolarização e da nova normatização geral da organização escolar de seus agentes e novas funções (Boynard et al., 1972). Foi um periodo em que vários serviços foram criados em âmbito federal e nos estados com funções de assessoria, orientação ou assistência pedagógica às escolas e seus profissionais. Com a reorganização das escolas foram também propostas novas perspectivas teóricas para os componentes curriculares acompanhados de nova concepção didática para seu ensino: atividades (globalizadas) para as séries iniciais do $11^{\circ} \mathrm{grau} ;$ matérias nucleadas para as séries finais do ensino de $1 .{ }^{\circ}$ grau e disciplinas para as do $2 .^{\circ}$ grau, finalizando a educação anterior ao ensino superior. Essas alterações causaram verdadeira reviravolta, fato que obrigou imensa oferta de cursos de aperfeiçoamento aos diferentes agentes das escolas entre outras providências. No estado de São Paulo, por exemplo, houve a disseminação do material denominado Guias Curriculares Propostos para as Matérias do Núcleo Comum do Ensino de $1^{\circ}$ Grau (São Paulo, 1975) preparado por equipes para toda a rede estadual, contendo detalhamento de objetivos e conteúdos articulados série a série, da $1 .^{a}$ a $8 .^{a}$, em todos os componentes curriculares. Já nos últimos anos da década de 1980, a estratégia foi composta por cursos conveniados com universidades, inclusive já contando com discussões sobre a implantação do Ciclo Básico nas séries iniciais, eliminando a repetência no $1 .^{\circ}$ ano (Marin \& Guarnieri, 1990).

Além de certa similaridade na esfera política entre os dois paises na época, é possivel detectar também a insuficiência de medidas adotadas nesse periodo, pois nos anos de 1980 a Argentina ingressou no segundo periodo conforme visto anteriormente. Aguerrondo (2004) aponta que os cursos de aperfeiçoamento, que vinham sendo desenvolvidos na Argentina, foram objeto de estudo verificando-se o pouco efeito deles no que se refere à formação em serviço. Identifica-se que não bastava apenas aperfeiçoar os professores, ainda que por razões diversas em ambos 
os países como será apontado a seguir. Nesse período, o termo aperfeiçoamento praticamente desapareceu e a palavra capacitação passou a ser a de maior uso ao lado de atualização que demonstrou crescimento notável.

Segundo Serra (2004) foi a Resolução n. ${ }^{\circ} 9$ do Conselho Federal de Cultura e Educação, de 1990 , que apresentou definições relativas aos novos processos de formação dos professores, por exemplo, determinando essa formação como um processo que incluísse: formação, capacitação, ${ }^{11}$ especialização, atualização e aperfeiçoamento para fazer face às novas propostas curriculares. O Ministério da Educação procurando exercer mecanismos regulatórios por meio da definição dos desenhos curriculares definiu orientação para fortalecer os esquemas de decisão dos docentes como caminho legítimo para que as novas propostas sejam traduzidas efetivamente na prática, supondo circulação das informações, com contribuição de especialistas e da participação ativa dos docentes e das instituições na elaboração da nova configuração (Recomendación n. 21 de 1992).

Alguns anos depois, a sanção da Ley Federal de Educación de 1993,12 determinou os seguintes objetivos para a formação docente, de acordo com o artigo 19:

a) Preparar y capacitar para un eficaz desempeño en cada uno de los niveles del sistema educacional y en las modalidades mencionadas posteriormente en esta ley;

b) Perfeccionar con criterio permanente a graduados y docentes en actividad en los aspectos científico, metodológico, artístico y cultural. Formar investigadores y administradores educativos. (grifos nossos)

Além disso, o poder executivo nacional, por meio de ministério específico deveria, entre outras atribuições, de acordo com o art. 53:

g) Promover y organizar concertadamente en el ámbito del Consejo Federal de
Cultura y Educación, una red de formación, perfeccionamiento y actualización del personal docente y no docente del sistema educativo nacional. (grifos nossos)

Nessa mesma década, a legislação brasileira - Lei de Diretrizes e Bases da Educação Nacional - promulgada em 1996, alterou novamente a organização do ensino, pois agora só existem dois niveis: o básico obrigatório englobando a educação infantil como obrigatória desde a lei 12.796/2013 até o ensino médio e o nível superior não obrigatório abrangendo o ensino realizado em universidades e faculdades isoladas. A educação infantil de zero aos quatro anos é facultada às familias que optem por esse atendimento, mas esse deve ser posto à disposição da população pelas várias redes escolares. A partir dos quatro anos esse atendimento passou a compor o nivel básico de ensino, portanto obrigatório a todas as crianças. No que tange ao tema aqui focalizado, há diversos artigos dentre os quais selecionamos dois por sua especificidade e porque nos demais há repetição de termos:

Art.63 - Os institutos superiores de educação manterão:

(...) Ill- programas de educação continuada para os profissionais de educação dos diversos niveis; (...)

Art.67- Os sistemas de ensino promoverão a valorização dos profissionais da educação, assegurando-lhes, inclusive nos termos dos estatutos e dos planos de carreira do magistério público

(...) II- aperfeiçoamento profissional continuado, inclusive com licenciamento periódico remunerado para esse fim; (...). (Saviani, 1997. pp. 181-182, grifos nossos)

As definições acima deixaram de vigorar com o cancelamento dos Institutos Superiores de Educação transferindo para a legislação mais recente e especifica para formação de professores, de 2009, mediante o Decreto n. 6755 que instituiu a Política Nacional de Formação de Profissionais do Magistério da Educação Básica, de onde

\footnotetext{
11 Utiliza-se aqui o termo capacitação que, segundo Torres, no espanhol, embora tenha o mesmo de sentido de formação, está mais ligado à capacitação em serviço (Torres, 1996, p. 160)

12 De acordo com a Ley Federal de Educación (1993): Educação inicial: 3-5 anos de idade (sendo obrigatório o último curso deste nível): Educação geral básica (EGB): 6-14 anos (educação obrigatória - dividida em três ciclos de três anos); Educação polimodal: 15-17 anos (trajetos técnicos profisionales - TTP - oferecem opções de especialização que complementam esse nivel e outorgam títulos técnicos).
} 
extraimos alguns princípios e um artigo regulamentador. Os principios sobre esse tema são:

IX- a eqüidade no acesso à formação inicial e continuada, buscando a redução das desigualdades sociais e regionais;

X- a articulação entre formação inicial e formação continuada, bem como entre os diferentes niveis e modalidades de ensino;

XI- a formação continuada entendida como componente essencial da profissionalização docente, devendo integrar-se ao cotidiano da escola e considerar os diferentes saberes e a experiência docente. (Brasil, 2009, grifos nossos)

Além desses princípios, um dos artigos explicita as formas de discurso sobre o tema:

Art. 8 - (...) $\S 2^{\circ}$ - As necessidades de formação continuada de profissionais do magistério serão atendidas por atividades formativas e cursos de atualização, aperfeiçoamento, especialização, mestrado ou doutorado. (Brasil, 2009, grifos nossos)

A Ley de Educación Nacional, de $2006^{13}$ contempla artigos que tratam de modo explícito os objetivos da atualidade:

Art. 72 (...) A formação docente como parte da educação superior tendo como função, entre outras, a formação inicial, a formação docente contínua, o apoio pedagógico às escolas e a investigação educativa ; (...)

Art. 73 (...) Oferecer diversidade de propostas e dispositivos de formação posterior a formação inicial que fortaleçam o desenvolvimento profissional dos docentes de todos os niveis e modalidades de ensino (...)

Art. 73 (...) Planejar e desenvolver o sistema de formação docente inicial e continua ; (...)

Art. 74 (...) O Ministério da Educação, Ciência e Tecnologia e o Conselho Federal de Educação acordarão as seguintes ações politicas: planos da formação docente inicial; diretrizes para a organização e administração do sistema e os parâmetros de qualidade que orientem os desenhos curriculares; ações que garantam o direito a formação continua a todos os docentes do pais, em todos os niveis e modalidades, assim como a gratuidade da oferta estatal da capacitação. (grifos nossos)

Como se depreende desses dados apresentados, tanto na Argentina quanto no Brasil, os discursos oficiais sobre a educação continuada dos professores foram se alterando ao longo das décadas, sobretudo nas duas últimas. Essa é uma característica comum, ainda que não coincidam as datas, fatos que estão a merecer novos estudos.

Segundo a documentação consultada, a alteração ocorrida em ambos os paises, que passaram a usar outros termos além de aperfeiçoamento muito presente nas décadas iniciais, pode ser interpretada devido ao fato de que, nas décadas de 1960 e 1970, a formação dos professores era suficiente para o desenvolvimento dos trabalhos do ensino, bastando que houvesse oportunidades de aperfeiçoar sempre, pautado em um significado de buscar alguns saberes em lugar de outros conforme as constantes mudanças (Marin, 1995) para o desempenho de uma função que, em décadas anteriores, ocorria sem problemas maiores. No Brasil, entretanto, essa necessidade passou a ser muito maior com a expansão da escolaridade e, depois, com a Lei n. ${ }^{\circ}$ 5692, de 1971, já apontada anteriormente, que alterou profundamente a organização e oportunizou a expansão da escolaridade para a população para além do primário com a eliminação dos exames entre primário e ginásio. O Pais passou de sete milhões de matriculados no ensino primário, no início da década de 1960, para cerca de treze milhões nos anos de 1970; e cerca de um milhão de alunos no secundário para cerca de quatro milhões nos anos de 1970 (Romanelli, 1995). Sem dúvida, um crescimento brutal atendendo a uma população que não tinha acesso anteriormente e que só ampliou nos anos subsequentes.

Com tal situação de expansão, que é positiva, entretanto, temos o início dos estudos que apontam problemas de evasão e de repetência, denotando a inadequação do atendimento, consequentemente gerando a insistência na formação continuada de um professorado que, oriundo de outras décadas atuando junto à camada mais homogênea da população, passou a enfrentar enormes grupos de alunos de origem bem diversi-

13 Com a Ley Nacional de Educación (2006), o sistema de ensino argentino compreende a educação inicial com os jardins maternais e de infantes (até 5 anos de idade); a educação primária tem como público alvo crianças de 06 a 12 anos; a educação secundária atende adolescentes e jovens que tenham concluído a etapa a educação primária. 
ficada levando à retomada de estudos constantes diante do novo alunado enfrentando, portanto, muitos desafios. Altera-se, então, o discurso: agora são necessárias atividades de atualização, pois há novas e urgentes quantias de professorado requisitado nem sempre preparado com formação adequada para atender esse volume de matrículas e suas escolas, até porque o número de professores leigos era bem elevado, situado na casa dos milhares no país. No ano de 1991. portanto décadas após tais modificações, menos de $20 \%$ dos professores que atuavam no país no ensino fundamental só possuíam quatro anos de estudos na escola fundamental (INEP, 2003) fato que gerou o uso do termo capacitação, ou seja,

(...) é preciso que as pessoas se tornem capazes, que adquiram as condições de desempenho próprias da profissão. Há embutida nesse termo, a meu ver, a ruptura com as concepções genéticas ou inatistas da atividade educativa, segundo as quais a dedicação ao magistério se deve a dom inato (...). (Marin, 1995, p. 17)

Em outras circunstâncias, altera-se o discurso para atender às necessidades da reorganização das escolas; entra em cena, também, a atualização para adquirir as novas orientações presentes na legislação e todo o suporte teórico subjacente a partir de 1971. Esses dados são substancialmente diversos da realidade argentina pois, como visto, a Argentina fez nova alteração na década de 1980, o que não ocorreu no Brasil.

No caso do Brasil, apesar de toda a previsão e as tentativas de tal atualização, a formalidade das propostas da nova legislação não conseguiu evitar a manutenção de muitos dos aspectos vigentes anteriormente na realidade das escolas do país, que possui algumas dificuldades para implantações como essas: o tamanho territorial e o volume de população a ser atendida, aliados à diversidade econômica, social e cultural das regiões permitem que apontemos a concordância com as considerações de Viñao (2000) sobre a cultura dos reformadores e gestores quando pretendem a generalização de medidas em contraste com as características de cada lugar e de cada escola, apesar do marco jurídico formal ser o mesmo.

Na Argentina, a alteração significativa do sistema educacional ocorrida com a Ley Federal n. 24.195 (1993), no entanto, por características próprias e políticas do país, os desdobramentos foram diferentes em cada região do país, ou seja, nas províncias. ${ }^{14}$ Apesar da previsão do Conselho Federal de Cultura e Educação como responsável pelos acordos que envolvessem jurisdições, províncias ou a cidade autônoma de Buenos Aires, em relação à adequação progressiva da estrutura educativa e seus desdobramentos, verifica-se a forte discussão e disparidade em relação à autonomia de cada região ou província, diante de sua força política e econômica para resistir ou aderir a uma política de estado. Isso refletiu diretamente na formação dos professores, seja no preparo inicial para a profissão ou em relação à capacitação dos docentes em serviço, pois houve uma grande sensação de instabilidade. No caso argentino, a caracterização dos ciclos e níveis de estrutura de ensino, os objetivos e os conteúdos básicos comuns (CBC) dos curriculos desses distintos niveis e ciclos levou à busca de cursos de capacitação e de atualização envolvendo questões semelhantes ao caso brasileiro em relação à necessidade de adequação às novas realidades e mudanças a partir da reforma do sistema educacional. Essa é uma situação bem diversa do Brasil cuja legislação é definida para todo o país sem autonomia quanto às definições, mas possivel quanto à forma do atendimento à formação continuada.

Quando chega a década de 1990, a Argentina tem todos os seus professores do início da escolarização formados em nível superior enquanto, no Brasil, a situação é bem diversa. Em 2006 ainda havia cerca de 140 mil professores leigos, isto é, sem formação para a docência obtida em nivel médio atuando nas séries iniciais do ensino fundamental (equivalente ao ensino primário) (Gatti \& Barreto, 2009). Para atender parte dessas necessidades de formação, foram criados os cursos especiais de formação em nível superior,

14 Um exemplo disso é tratado por Miranda et al. (2006), que discutem as novas configurações emergentes a partir da Ley Federal de Educación Argentina e sua implementação na província de Córdoba. 
sendo, um deles, objeto de estudo deste projeto de pesquisa coletivo. Precisariam ser formados, no Brasil, cerca de 600 mil professores para atuar nessas séries iniciais, segundo o patamar de formação estipulado pela legislação de 1996: a certificação de ensino superior.

Neste sentido, a partir da década de 1990, os discursos se alteram na legislação com o uso bem mais frequente de formação contínua ou continuada, tanto no Brasil quanto na Argentina, termo abordado com significados de continuidade da formação inicial. Trata-se de modalidade de discurso oriundo da construção conceitual acadêmica, em um percurso de adaptação a cada realidade de acordo com suas peculiaridades. Assim, embora com o mesmo termo, o seu uso porta significados diferentes, posto que é utilizado para situações educacionais bem discrepantes, conforme apontado anteriormente. São dados como esses e os do parágrafo anterior que permitem analisar as situações e não cair em considerações de abstracionismo como apontam Bourdieu e Passeron (1979), mas compreender as realidades.

Em 2003, o Ministério da Educação, Ciência e Tecnologia argentino iniciou uma revisão da política de formação de professores à luz de novos critérios, entre eles: visualização da formação docente como um processo contínuo e com necessidades práticas dos docentes em aula como foco principal dos programas de formação em serviço; programas específicos centrados nos problemas de ensino em condições adversas; diversificação das instituições e articulação dos sistemas institucionais de formação docente continua; articulação das políticas de desenvolvimento profissional com a carreira docente; aproveitamento das Tecnologias de Informação e Comunicação (TIC).

Começa-se a perceber o docente já não como 'carente' das qualificações necessárias para a mudança, mas como ator protagonista das reformas e se centra o interesse na mudança de sua atitude, já que se entende que sem essa mudança não pode haver mudança de sua prática. Inicia-se a reconceitualização dessas atividades, para a idéia de desenvolvimento profissional. (Aguerrondo, 2004, p. 19, grifos nossos)

Diante dessa percepção começaram a ser incluidos aspectos de capacitação e de formação mais relacionados com a função docente ${ }^{15}$ e não somente com os conteúdos curriculares que eles deveriam dominar, além de questões sociais que se destacavam no ambiente escolar e um conjunto de temas voltados para o "mundo contemporâneo", com a convicção de que, se não se tem certa formação ou representação para as questões postas na sociedade vigente, não é possivel entender o que se passa nas familias e na comunidade em que os alunos estão inseridos.

Portanto, além de reafirmar o termo formação e educação contínua ou continuada, após a década de 1990 passa-se a utilizar o discurso da formação pautada no termo desenvolvimento profissional, que engloba outras facetas da função docente que não apenas o ensino.

Na esteira das pesquisas internacionais da década (Marcelo, 1998) essa forma de discurso passa a ser corrente, pois se considera a necessidade de incentivar a análise de várias dimensões em uma perspectiva mais global e sistêmica, pois são muitas as atividades a serem realizadas pelos professores no interior das escolas. No Brasil, o termo é de uso corrente nas propostas desenvolvidas com os professores, embora não constante na legislação. Já na Argentina o termo está presente na regulamentação, conforme visto anteriormente.

É possivel detectar que, tanto no Brasil quanto na Argentina, ocorre a circulação das ideias garantidas pela sua divulgação, pois são muitos os termos e, por último, vigoram os discursos sobre o desenvolvimento profissional como resultado da produção acadêmica nos diferentes países (Marcelo, 1998). Acrescente-se as negociações que se fizeram, e fazem, em grandes encontros internacionais envolvendo os governos dos países

\footnotetext{
15 Artículo 71: La formación docente tiene la finalidad de preparar profesionales capaces de enseñar, generar y transmitir los conocimientos y valores necesarios para la formación integral de las personas, el desarrollo nacional y la construcción de una sociedad más justa. Promoverá la construcción de una identidad docente basada en la autonomía profesional, e vínculo con la cultura y la sociedad contemporánea, el trabajo en equipo, el compromiso con la igualdad y la confianza en las posibilidades de aprendizaje de los/as alumnos/as (Ley Nacional de Educación n. 26, 2006).
} 
nos acordos, haja vista a Declaração de Educação para Todos, ocorrida em Jomtien em 1990 (Shiroma et al., 2011); as estratégias do Banco Mundial e do Banco Interamericano de Desenvolvimento (De Tommasi, Warde, \& Haddad, 1996) e a Declaração de Dakar, de 2000 (Universidade de São Paulo, 2017) entre outras oportunidades e ações.

É por esses percursos que as ideias e teorias desenvolvidas em diferentes centros são apropriadas pela legalidade mediante a aceitação de interesses de grupos, ideologias e opiniões para, em um outro passo, chegar às práticas nos sistemas de ensino. Tais passagens são sempre complexas e demandam tempo para sua ocorrência, segundo Viñao (2000), indicando que sua compreensão ampla e profunda só pode ser apreendida na longa duração. Apesar de ser preciso levar em conta como cada lugar e cada época se apropriam de suas práticas, inclusive discursivas, para a formação de seus sujeitos, foi possivel detectar que, em ambos os países, os discursos sobre educação continuada tiveram, subjacente, a perspectiva da adequação dos professores às novas políticas, propiciando ajustes na socialização alinhada ao exercício de suas funções, parte da insignia geral "investir nas pessoas" para aumento do capital humano (Coraggio, 1996) em todas as esferas da vida social.

\section{Algumas considerações}

É possivel, neste momento, sintetizar algumas similaridades e algumas diferenças entre as épocas e os discursos do Brasil e da Argentina.

Detectam-se similaridades porquanto as ações politicas e seus desdobramentos emanam das mesmas matrizes internacionais, como apontado anteriormente, com interpretações parecidas, mas com desdobramentos, às vezes, diferenciados dadas as condições dos sujeitos e as realidades locais, incluindo questões históricas de cada país. Parecem similares as várias ações destinadas à formação continuada que destacam a adequação do trabalho docente às novas demandas institucionais, geralmente vinculadas à implementação de reformas curriculares e de níveis de ensino, ainda que a formação continuada na Argentina não tenha tido como objetivo titular os professores em serviço, situação presente em algumas ações brasileiras.

No primeiro período analisado, de 1950 até meados de 1980, iniciam-se, tanto no Brasil quanto na Argentina, os discursos voltados ao aperfeiçoamento dos professores, pois apesar da preparação dos docentes ser centrada na formação inicial nos cursos de preparação para ingresso na carreira docente - considerada o lugar de todo o saber relevante para a prática profissional - começa-se a questionar essa formação e o quanto atende às necessidades. As transformações econômicas, sociais e científicas desse período desencadearam crises nos sistemas educativos e ações políticas para a melhoria e a ampliação da formação docente exigindo revisões também nos discursos, ocasionando, nos anos seguintes, praticamente o desaparecimento do termo aperfeiçoamento e a utilização das palavras atualização e capacitação, com um significado muito forte no sentido de suprir as deficiências da formação inicial, tratando de questões a respeito do preparo e da adaptação dos professores para a nova perspectiva educacional.

Na Argentina, por exemplo, as questões envolvendo conteúdos curriculares - que deveriam servir como base para o novo sistema educativo demonstravam a necessidade de novos aprendizados, inclusive conceituais e teóricos, sendo criada uma Rede Federal de Formação Docente Contínua como tentativa de mecanismo regulatório dos cursos de capacitação docente que permeou a década de 1990, chegando ao fracasso no início dos anos 2000, após muita resistência política no país e indicando uma nova perspectiva pautada em outro discurso, o de desenvolvimento profissional, que abrange a ideia de continuidade da formação inicial de maneira continuada, conforme caracterizado na nova Lei Nacional de Educação em 2006. Esse discurso, portanto, já vem se desenvolvendo no Brasil, desde meados da década de 1990, desencadeando discussões a respeito das (novas) funções do professor, aspectos discutidos também no âmbito internacional.

Percebe-se que muitas questões presentes neste contexto destacam aspectos de políticas 
educacionais que percorreram a América Latina promovendo reformas pautadas em discursos oficiais de internacionalização de mudanças significativas. De modo geral, essas reformas expressaram a instalação de um conjunto de dispositivos estatais com o propósito declarado de regular e promover a suposta melhoria das escolas e de reconfiguração dos sistemas educativos, impactando diretamente na formação. Este estudo procurou verificar aspectos de especificidades dos desenvolvimentos nacionais ou possiveis semelhanças nos contextos de organização e de inserção educacional, com um olhar atento especialmente na direção dos discursos a respeito da formação de professores, considerados peças-chave nesse contexto internacional.

\section{Referências}

Aguerrondo, I. (2004). Os desafios da política educacional relativos às reformas da formação docente. In Ofício de professor na América Latina e Caribe. Trabalhos apresentados na Conferência Regional O desempenho dos professores na América Latina e no Caribe: novas prioridades - Brasilia, julho de 2002. Fundação Victor Civita.

Birgin, A. (2012). Introducción: La formación, ¿una varita mágica? In Birgin, A., Más allá de la capacitación: debates acerca de la formación docente en ejercicio ( $1^{\text {a }}$ ed.). Buenos Aires: Paidós.

Bourdieu, P. \& Passeron, J. C. A. (1979). Comparabilidade dos sistemas de ensino. In Durand, J. C. G. (Org.), Educação e hegemonia de classe as funções ideológicas da escola (pp. 69-104). Rio de Janeiro: Zahar.

Boynard, A. P., Garcia, E. C., \& Robert, M. I. (1972). A reforma do ensino - Lei 5692/1971. São Paulo: Livros Irradiantes.

Lei n. 4026 de 20 de dezembro de 1961. Fixa as Diretrizes e Bases da Educação Nacional. Recuperado de https://www2.camara.leg.br/legin/fed/lei/1960-1969/ Lei-4024-20-dezembro-1961-353722-publicacaooriginal-1-pl.html

Lei n. 9394 de 20 de dezembro de 1996. Estabelece as Diretrizes e Bases da Educação Nacional. Recuperado de http://www.planalto.gov.br/ccivil_03/leis/l9394.htm

Ley Federal de Educación n. 24.195 (1993). Ministerio de Cultura y Educación de la Nación. Consejo Federal de Cultura y Educación. Buenos Aires.

Ley Nacional de Educación n. 26 (2006). Ministerio de Cultura y Educación. Buenos Aires.
Decreto $n^{\circ} 6755$, de 29 de janeiro de 2009. Institui a Política Nacional de Formação de Profissionais do Magistério da Educação Básica, disciplina a atuação da Coordenação de Aperfeiçoamento do Pessoal de Nivel Superior-CAPES no fomento a programas de formação inicial e continuada, e dá outras providências. Brasília: Casa Civil da Presidência da República Federativa do Brasil/Subsecretaria para Assuntos Jurídicos. Diário Oficial da União. Recuperado de http://www planalto.gov. br/ccivil_03/_ato2007-2010/2009/decreto/d6755.htm

Coraggio, J. L. (1996). Propostas do Banco Mundial para a educação: sentido oculto ou problemas de concepção? In De Tommasi, L., Warde, M. J., \& Haddad, S., O Banco Mundial e as politicas educacionais (pp. 75-123). São Paulo: Cortez Editora; Ação Educativa.

Davini, M. C. (1998). El curriculum de formación del magisterio. Planes de estudio y programas de enseñanza. Buenos Aires: Miño y Dávila Editores.

De Tommasi, L., Warde, M. J. \& Haddad, S. (Orgs.). (1996). O Banco Mundial e as Politicas Educacionais. São Paulo: Cortez.

Ferrer, F. (2002). La educación comparada actual. Barcelona: Ariel.

Gatti, B. A. \& Barretto, E. S. S. (2009). Professores do Brasil: impasses e desafios. Brasília: Unesco.

Instituto Nacional de Estudos e Pesquisas Educacionais Anísio Teixeira. (2003). Estatísticas dos professores no Brasil. Brasilia: Inep.

Marcelo, C. (1998, setembro/dezembro). Pesquisa sobre a formação de professores: o conhecimento sobre aprender a ensinar. Revista Brasileira de Educação, 9, 51-75. Recuperado de http://anped.tempsite.ws/novo_portal/ rbe/rbedigital/rbdeog/rbdeog_06_carlos_marcelo.pdf

Marin, A. J. (1995). Educação continuada: introdução a uma análise de termos e concepções. Cadernos Cedes, 36, 13-20

Marin, A. J. \& Guarnieri, M. R. (1990). Educação continuada dos profissionais de ensino: estudo da participação da UNESP no convênio com a Secretaria da Educação. Anais do Congresso Estadual Paulista sobre Formação de Educadores, 1, 73-73.

Miranda, E. M. M. et al. (2006). Politicas de reforma del sistema educativo en los noventa: nuevas configuraciones emergentes a partir de la Ley Federal de Educación y su implementación en Córdoba. Cordoba: Ed. Brujas.

Resolución n. og (1990). Ministerio de Cultura y Educación de la Nación. Consejo Federal de Cultura y Educación. Buenos Aires.

Recomendación n. 21 (1992). Ministerio de Cultura y Educación de la Nación. Consejo Federal de Cultura y Educación. Buenos Aires.

Riquelme, G. et al. (1998). Politicas y sistemas de formación - Universidad Nacional de Buenos Aires. Formación de formadores - serie Los documentos $n^{\circ} 8$. Buenos Aires.

Romanelli, O. O. (1995). História da Educação no Brasil (1930-1973). Petrópolis: Vozes. 
Elaine Gomes Matheus Furlan · Alda Junqueira Marin

São Paulo. (1975). Guias Curriculares Propostos para as Matérias do Núcleo Comum do Ensino de $1^{\circ} \mathrm{Grau}$. São Paulo: Secretaria da Educação/SP.

Saviani, D. (1997). A nova lei da educação. Campinas: Autores Associados.

Shiroma, E. O., Moraes, M. C. M., \& Evangelista, O. (2011). Politica educacional ( $4^{\mathrm{a}}$ ed.) Rio de Janeiro: Lamparina.

Serra, J. C. (2004). El campo de capacitación docente. Politicas y tensiones en el desarrollo profesional. Buenos Aires: Miño y Dávila Editores.

Torres, R. M. (1996). Melhorar a qualidade da educação básica? As estratégias do Banco Mundial. In De Tommasi, L., Warde, M. J., \& Haddad, S. (Orgs.), O Banco Mundial e as Politicas Educacionais (pp. 125-193). São Paulo: Cortez.

Universidade de São Paulo. (2017). Declaração de Dakar. Educação para todos. 2000. In USP - Biblioteca Virtual de Direitos Humanos. Recuperado em outubro de 2017 de www.direitoshumanos.usp.br/index.php/ Direito-a-Educacao/declaracao-de-dakar.html

Viñao, A. (2000, julho/dezembro). Culturas escolares y reformas. Sobre la naturaleza histórica de los sistemas e instituciones educativas. Teias, Rio de Janeiro, 1(2), 99-133.

\section{Elaine Gomes Matheus Furlan}

Doutora em Educação pelo Programa de Estudos Pós-Graduados em Educação: História, Política, Sociedade da Pontifícia Universidade Católica de São Paulo (PUC-SP), em São Paulo, SP, Brasil; professora e pesquisadora do Departamento de Ciências da Natureza, Educação e Matemática e do Programa de Pós-Graduação em Educação em Ciências e Matemática da Universidade Federal de São Carlos (UFSCar), Araras, SP, Brasil.

\section{Alda Junqueira Marin}

Livre Docente em Didática pela Universidade Estadual Paulista (Unesp); professora e pesquisadora do Programa de Estudos Pós-Graduados em Educação: História, Política, Sociedade da Pontifícia Universidade Católica de São Paulo (PUC-SP), em São Paulo, SP, Brasil.

\section{Endereço para correspondência}

Elaine Gomes Matheus Furlan

Universidade Federal de São Carlos

Centro de Ciências Agrárias

Rodovia Anhanguera, Km 174, SP-330

$13600-970$

Araras, SP, Brasil
Alda Junqueira Marin

Pontifícia Universidade Católica de São Paulo

Rua Monte Alegre, 984

Perdizes, 05014-901

São Paulo, SP, Brasil 